\title{
PENGGUNAAN MINYAK ALAMI DENGAN MINIMUM QUANTITY LUBRICATION TERHADAP HASIL PROSES BUBUT AA 6061
}

\author{
Putu Hadi Setyarini \\ Tenaga Pengajar (Dosen) \\ Universitas Brawijaya \\ Jurusan Teknik Mesin \\ putu_hadi@ub.ac.id \\ Khairul Anam \\ Tenaga Pengajar (Dosen) \\ Universitas Brawijaya \\ Jurusan Teknik Mesin \\ khairul.anam27@ub.ac.id \\ Muhammad Wahyudi \\ Mahasiswa S1 \\ Universitas Brawijaya \\ Jurusan Teknik Mesin \\ moh.wahyudi27@gmail.com
}

\begin{abstract}
Environmentally friendly lubricants are lubricants that are easily dissolved in the environment and are not harmful to the ecosystem. It uses to reduce the heat in the contact area so that the machinability of the workpiece and the ability of the chisel will increase. To minimize the use of bio-cutting fluids, lubrication is carried out by minimum drop lubrication in the lathe process. The purpose of this research is to comply with the surface roughness of the workpiece and the shape of the chip. The material used is aluminum 6061, the natural oil used are rubber seed oil, virgin coconut oil, sunflower seed oil, and castor oil. The turning parameters were the depth of cut $0.5 \mathrm{~mm}$, spindle speed of 330 rpm, feed rate $0.231 \mathrm{~mm} / \mathrm{rev}$, tool angle 90o, drop lubrication 192 $\mathrm{ml} /$ hour, infeed length $100 \mathrm{~mm}$. The results of the research showed that virgin coconut oil has the lowest surface roughness. This is because the viscosity value of virgin coconut oil is very small so that the flow rate is able to work perfectly to lubricate the contact area. It has a thin chip configuration, the tool also wears but did not experience cracks.
\end{abstract}

Keywords: AA 6061, Turning Process, MQL, Natural Oil, Surface Roughness.

\section{PENDAHULUAN}

Selama proses permesinan berlangsung terjadi interaksi antara pahat dengan benda kerja [1]. Akibat dari interaksi ini, pahat akan mengalami keausan dan mempengaruhi kualitas permukaan benda kerja [2]. Untuk meminimalisir efek tersebut, diperlukan pelumas selama proses permesinan berlangsung. Pelumas yang selama ini dipakai kebanyakan merupakan pelumas dengan menggunakan minyak mineral yang berasal dari minyak bumi [3]. Jenis pelumas ini memiliki kekurangan yaitu susah didapatkan, harganya relatif mahal dan tidak ramah lingkungan, sehingga dikembangkanlah penggunaan minyak alami sebagai pelumas. Beberapa jenis minyak alami yang mulai banyak dipergunakan sebagai pelumas pada proses permesinan diantaranya adalah minyak bijih karet, minyak kelapa, minyak bijih bunga matahari dan minyak jarak [4 - 5]. Pelumas alami tersebut memiliki kandungan zat kimia rendah, sehingga mudah terurai dalam lingkungan serta memiliki indeks viskositas yang tinggi. Tingginya tingkat viskositas pada pelumas ini membuat penggunaan pelumas ini tidak sebanyak minyak mineral. Salah satu cara yang kini tengah banyak dikembangkan dalam penggunaan minyak alami ini adalah dengan menggunakan minimum quantity lubrication [6].

Penggunaan metode minimum quantity lubrication selama proses permesinan dilakukan dengan tingkat konsumsi minyak selama pengunaan sekitar $50-500 \mathrm{ml} / \mathrm{jam}$ dan dilakukan tanpa menggunakan udara bertekanan [7 - 8]. Metode tetesan ini memanfaatkan efek gravitasi sehingga dengan meminimumkan penggunaan pelumas dan bekerja secara tetes ke area bidang kontak antara pahat dan benda kerja, sehingga akan memberikan fungsi pendinginan dan pelumasan yang baik yang nantinya dapat menurunkan tingkat kekasaran permukaan dan meningkatkan umur pahat selama proses permesinan berlangsung [9].

Proses bubut merupakan salah satu proses permesinan yang banyak memerlukan pelumas untuk proses pendinginan [10 - 11]. Proses ini merupakan suatu proses pemakanan benda kerja yang diinginkan dengan alat potong yang bergerak secara translasi sejajar dengan sumbu putar dari benda kerja. Pada proses ini, karakteristik geometri memegang peranan penting dalam perencanaan mesin, yaitu hubungan dengan gesekan, keausan, pelumasan dan tahan kelelahan [12]. Dapat dijabarkan bahwa keausan merupakan hilangnya material dari permukaan benda padat, sebagaian hilang akibat dari gerakan mekanik dan akibat temperatur potong yang 
tinggi [13]. Keausan dapat timbul karena kontak langsung antara permukaan pahat dengan benda kerja, sedangkan temperatur yang tinggi pada saat pemotongan didapat dari energi pemotongan yang diubah menjadi panas memlalui proses gesekan antara chip dan bidang aktif dan antara pahat dengan benda kerja [14 - 15].

Penelitian ini dilakukan untuk mendapatkan kondisi optimal dari minyak alami terhadap kekasaran permukaan aluminium, bentuk chip dan keausan pahat saat proses bubut menggunakan metode MQL, sehingga didapatkan perbedaan pengaruh jenis minyak alami terhadap kekasaran permukaan, bentuk chip dan pengurangan volume pahat yang terjadi .

\section{METODE DAN BAHAN}

\subsection{Material yang Dipergunakan}

Material yang dipergunakan adalah aluminium 6061 dengan diameter 22 mm dan Panjang 200 mm serta memiliki komposisi sebagaimana tertera pada Table 1 berikut

Tabel 1: Komposisi AA 6061 (\%wt.)

\begin{tabular}{l|l}
\hline ELEMEN & PERSENT ASE (\%WT.) \\
\hline $\mathrm{Al}$ & 96.72 \\
\hline $\mathrm{Mg}$ & 0.95 \\
\hline $\mathrm{Si}$ & 0.5 \\
\hline $\mathrm{Fe}$ & 0.63 \\
\hline $\mathrm{Cu}$ & 0.25 \\
\hline $\mathrm{Cr}$ & 0.30 \\
\hline $\mathrm{Zn}$ & 0.25 \\
\hline $\mathrm{Ti}$ & 0.20 \\
\hline $\mathrm{Mn}$ & 0.10 \\
\hline Unsur lainnya & 0.10 \\
\hline
\end{tabular}

\subsection{Proses Bubut dengan MQL}

Aluminium 6061 dan pahat insert karbida diset pada chuck mesin bubut pada mesin bubut KW15-485 dan mengatur letak nozzle diantara mata pahat dan benda kerja. Setelah itu dilakukan peletakan dudukan alat yang sesuai agar proses pengukuran laju aliran bisa berjalan dengan baik. Dudukan alat merupakan alat pendukung untuk melakukan proses mengalirnya pelumas secara tetes ke pahat dan benda kerja. Dipersiapkan gelas ukur untuk mengetahui volume keluarnya pelumas, kemudian selang infus digunakan untuk mengalirkan dan katup infus digunakan untuk mengatur laju aliran pelumas selama 60 detik. Kemudian minyak kelapa dituangkan ke gelas ukur dengan volume konstan $250 \mathrm{ml}$ dalam keadaan katup selang infus tertutup. Dipergunakan laju aliran $192 \mathrm{ml} / \mathrm{s}$ diukur dengan cara membuka katup sedikit-sedikit dan diwaktu menggunakan stopwatch selama 1 menit (60 s), kemudian keluarnya pelumas ditampung di gelas ukur. Setelah benda kerja dan minyak alami sudah siap dapat dilakukan proses permesinan dengan depth of cut sebesar $0,5 \mathrm{~mm}$, kecepatan putar spindel $330 \mathrm{rpm}$, feed rate $0,231 \mathrm{~mm} / \mathrm{rev}$, sudut pahat $90^{\circ}$ dan panjang pemakanan: $100 \mathrm{~mm}$. Selanjuya dapat dilakukan proses pemotongan dengan variabel telah ditentukan dengan variasi minyak biji bunga matahari, minyak jarak, minyak kelapa, minyak biji karet dan minyak jarak.

\subsection{Pengujian Kekasaran Permukaan, Bentuk Chip dan Mikrostruktur}

Pengujian kekasaran permukaan dilakukan dengan menggunakan Mitutoyo SJ 201 pada permukaan aluminium 6061 yang setelah selesai dilakukannya proses permesinan. Pengukuran dilaksanakan pada bagian bawah, tengah, dan atas specimen dan diambil rata-rata data yang telah diambil. Sementara itu pengukuran chip dilakukan dengan menggunakan penggaris pada chip yang dihasilkan dari proses bubut yang sudah dilakukan dengan menggunakan berbagai jenis minyak alami. Untuk pengujian mikrostruktur dilaksanakan pada pahat yang tidak mengalami proses permesinan serta pahat yang diberikan proses permesinan dengan bermacammacam pelumas dari minyak alami. Pengujian dilakukan dengan menggunakan SEM Phenom dengan perbesaran $300 \mu \mathrm{m}$. 


\section{HASIL DAN DISKUSI}

Gambar 1 berikut menjelaskan hubungan penggunaan jenis minyak alami terhadap hasil kekasaran permukaan aluminium 6061 setelah melalui proses bubut dengan metode pendinginan menggunakan minimum quantity lubrication.

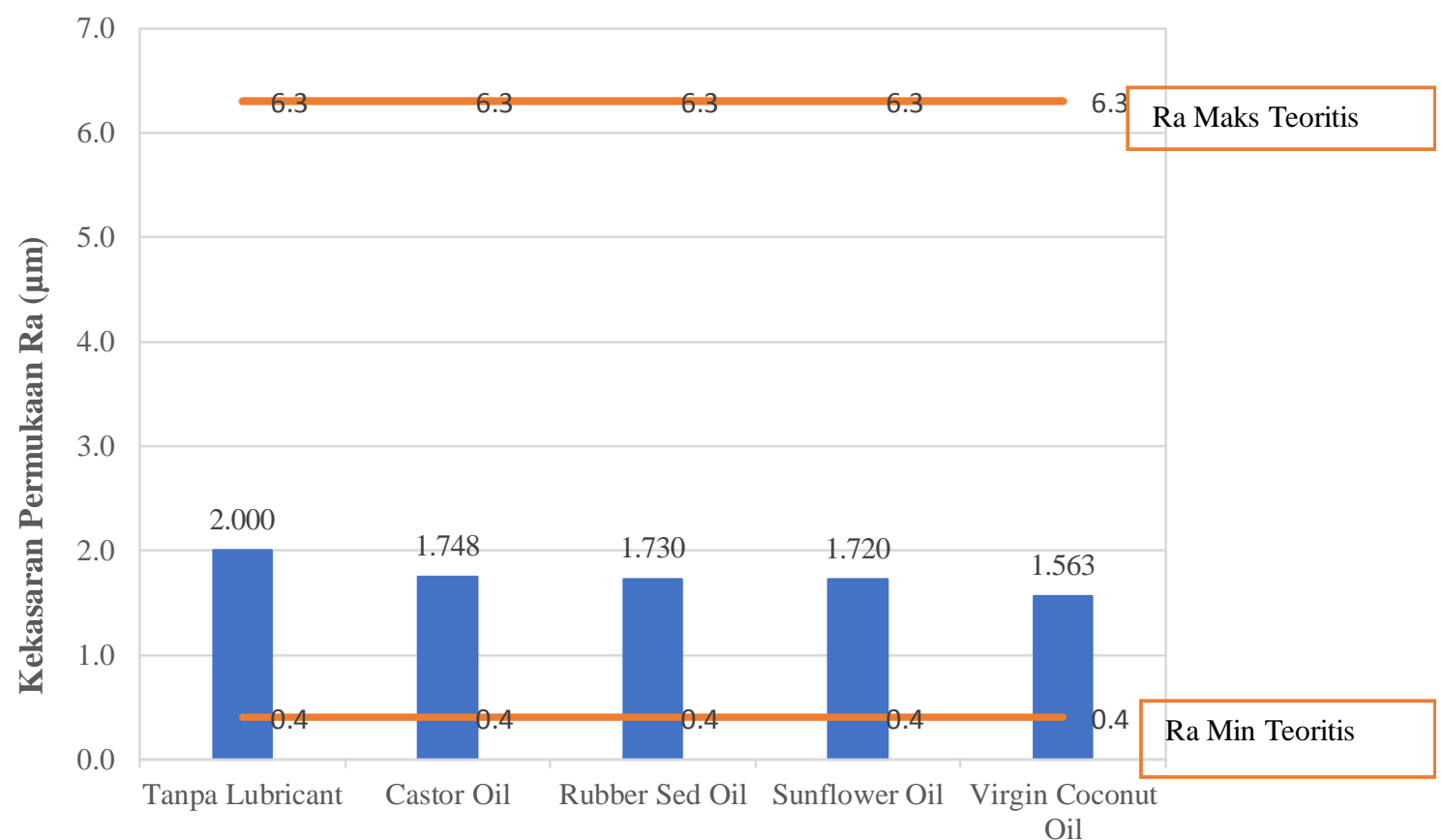

Gambar 1 Hubungan jenis minyak alamiterhadap kekasaran permukaan Ra

Nampak dari Gambar 1 bahwa kekasaran permukaan (Ra) yang diukur berada jauh di bawah kekasaran ratarata $(\mathrm{Ra})$ teoritis. Nilai kekasaran permukaan tertinggi diperoleh untuk specimen yang di bubut dengan tidak menggunakan pelumas, yaitu sebesar $2 \mu \mathrm{m}$. sedangkan untuk penggunaan minyak alami, kekasaran tertinggi berturut-turut dihasilkan oleh hasil bubut dengan menggunakan minyak biji bunga matahari dengan Ra 1.5627 $\mu \mathrm{m}$, minyak jarak dengan Ra $1.7297 \mu \mathrm{m}$, minyak biji karet dengan Ra $1.7203 \mu \mathrm{m}$, minyak biji bunga matahari dengan Ra $1.5627 \mu \mathrm{m}$, minyak kelapa dengan Ra $1.0843 \mu \mathrm{m}$. semakin menurunnya kekasaran permukaan yang diperoleh dengan penggunaan alami, menunjukkan semakin kecilnya nilai viskositas dari minyak tersebut. Specimen setelah proses bubut dengan menggunakan MQL minyak kelapa memiliki nilai kekasaran permukaan terendah dibandingkan dengan tanpa pelumasan dan dengan MQL menggunakan minyak alami lainnya. Hal ini dikarenakan nilai viskositas minyak kelapa sangat kecil sehingga laju aliran mampu bekerja secara sempurna untuk melumasi area bidang kontak.

Pada pelumasan dengan metode tetes menunjukkan keunggulan nilai kekasaran permukaan dibanding tanpa menggunakan pelumas. Dikarenakan pelumas jenis minyak alami mampu bertindak sebagai pendinginan serta melumasi pada area bidang kontak antara pahat dan benda kerja serta pahat mampu bekerja secara sempurna saat proses pembubutan, sehingga kekasaran permukaan yang dihasilkan juga akan lebih baik atau permukaan benda kerja semakin halus. Dan sebaliknya tanpa menggunakan pelumas menghasilkan Ra terbesar dibandingkan dengan metode tetes. Hal ini disebabkan karena tidak adanya pelumas ataupun pendinginan pada area bidang kontak antara pahat dan benda kerja. Gesekan yang terjadi menyebabkan timbul panas yang mengakibatkan kerusakan pada pahat sehingga mengakibatkan kekasaran permukaan yang tinggi.

Sementara itu bentuk chip yang dihasilkan dari proses proses permesinan untuk aluminium dengan laju aliran $192 \mathrm{ml} / \mathrm{jam}$ menggunakan pelumas jenis minyak alami dan tanpa menggunakan pelumas ditunjukkan pada Gambar 2. Dapat dilihat bahwa semakin bertambahnya viskositas maka perubahan pada bentuk chip akan lebih rata dan cenderung kontinu. Pada minyak kelapa dengan viskositas yang kecil akan menghasilkan chip kontinu sepanjang $650 \mathrm{~mm}$ dan memiliki ukuran terpanjang dibandingkan dengan yang lainnya. Namun pada chip yang dihasilkan dari proses bubut dengan menggunakan pelumas minyak jarak, minyak biji karet dan minyak biji bunga matahari terjadi perubahan bentuk chip. Demikian juga dengan chip yang dihasilkan tanpa 
menggunakan menggunakan pelumas. Bentuk chip yang dihasikan kurang sempurna dengan bentuk bersegmen.

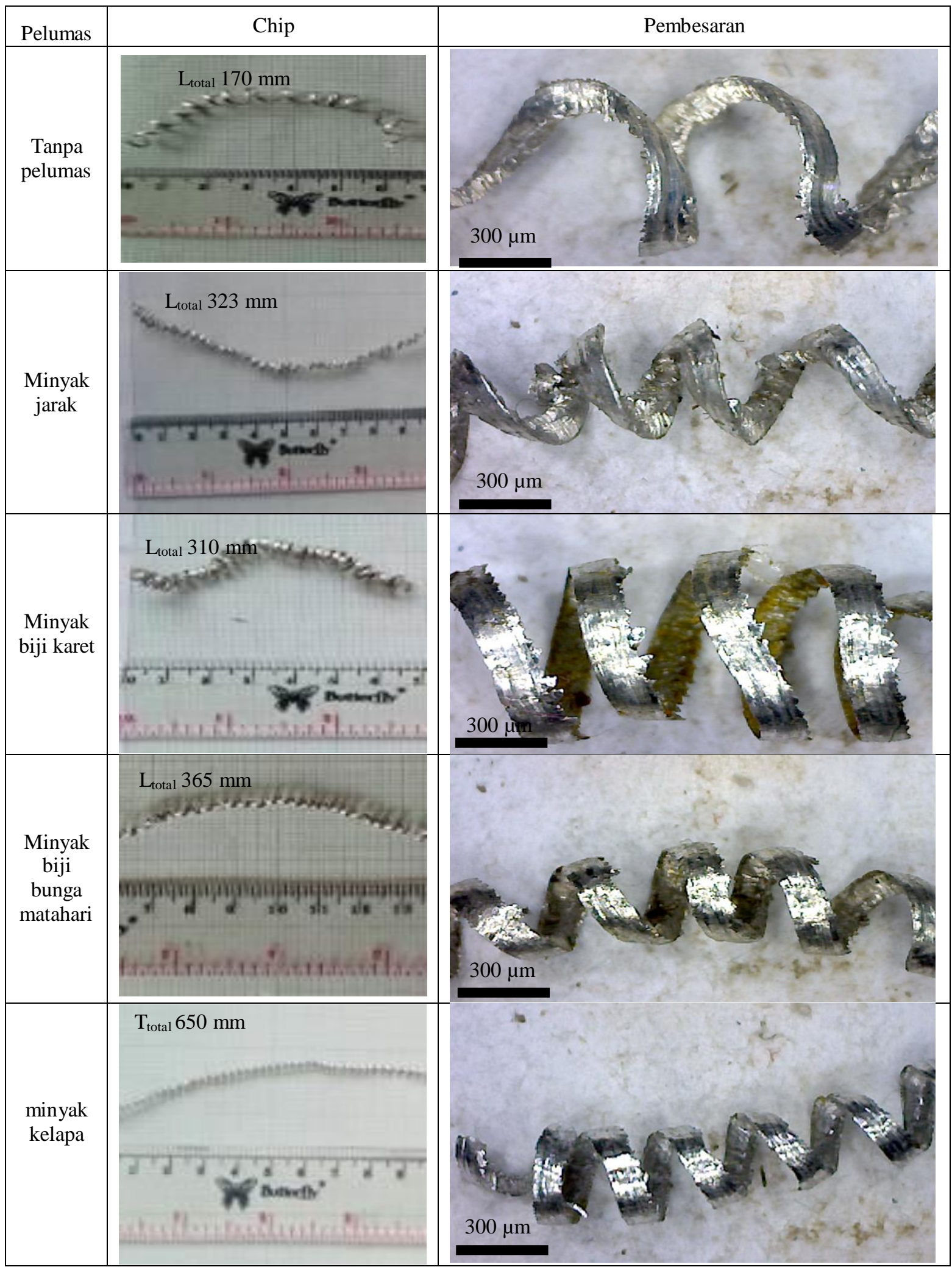

Gambar 2. Bentuk chip dengan menggunakan berbagai jenis pelumas

Hal ini dikarenakan panas yang dihasikan dari gaya gesek antara chip dan mendapat tekanan akan timbul tegangan didaerah sekitar konsentrasi gaya penekanan dari pahat dan pada salah satu arah akan terjadi tegangan 
geser yang maksimum. Apabila tegangan geser ini melebihi kekuatan logam yang bersangkutan maka akan terjadi deformasi plastis atau perubahan bentuk permanen yang menggeser dan memutus material chip di ujung pahat sebagaimana ditunjukkan pada bentuk chip yang diperoleh dari hasil proses permesinan tanpa menggunakan pelumas.

Tabel 2. Pengurangan Volume Pahat Setelah Proses Permesinan

\begin{tabular}{cccc}
\hline \multirow{2}{*}{ Jenis minyak alami } & $\begin{array}{c}\text { Volume Awal } \\
\left(\mathrm{V}_{0}\right)\end{array}$ & $\begin{array}{c}\text { Volume Akhir } \\
\left(\mathrm{V}_{1}\right)\end{array}$ & $\begin{array}{c}\text { Pengurangan Volume Pahat } \\
\left(\Delta \mathrm{V}=\mathrm{V}_{\mathrm{o}}-\mathrm{V}_{1}\right)\end{array}$ \\
\cline { 2 - 4 } & $\mathrm{cm}^{3}$ & $\mathrm{~cm}^{3}$ & $\mathrm{~cm}^{3}$ \\
\hline Minyak jarak & 6,12009 & 6,05726 & 0,062828 \\
\hline Minyak biji karet & 6,29821 & 6,25061 & 0,047601 \\
\hline Minyak biji bunga matahari & 6,24786 & 6,21017 & 0,037684 \\
\hline Minyak kelapa & 6,05074 & 6,01631 & 0,034421 \\
\hline Tanpa pelumas & 6,2778 & 6,10691 & 0,170889
\end{tabular}

Pada Tabel 2 dapat dilihat bahwa semakin tinggi viskositas akan mempengaruhi keauasan pahat saat proses bubut, ketika menggunakan pelumas minyak alamihingga tanpa menggunakan lubricant. Bahwa tanpa menggunakan lubricant keausan pahat lebih tinggi dibandingkan dengan menggunakan lubricant. Keausan tersebut timbul karena tidak terjadi pelumasan pada area bidang kontak sehingga timbul panas selama proses pemakanan aluminium yang mengakibatkan kekasaran permukaan lebih tinggi. Apabila dilihat dari mikrostruktur setelah proses bubut seperti Gambar 3.

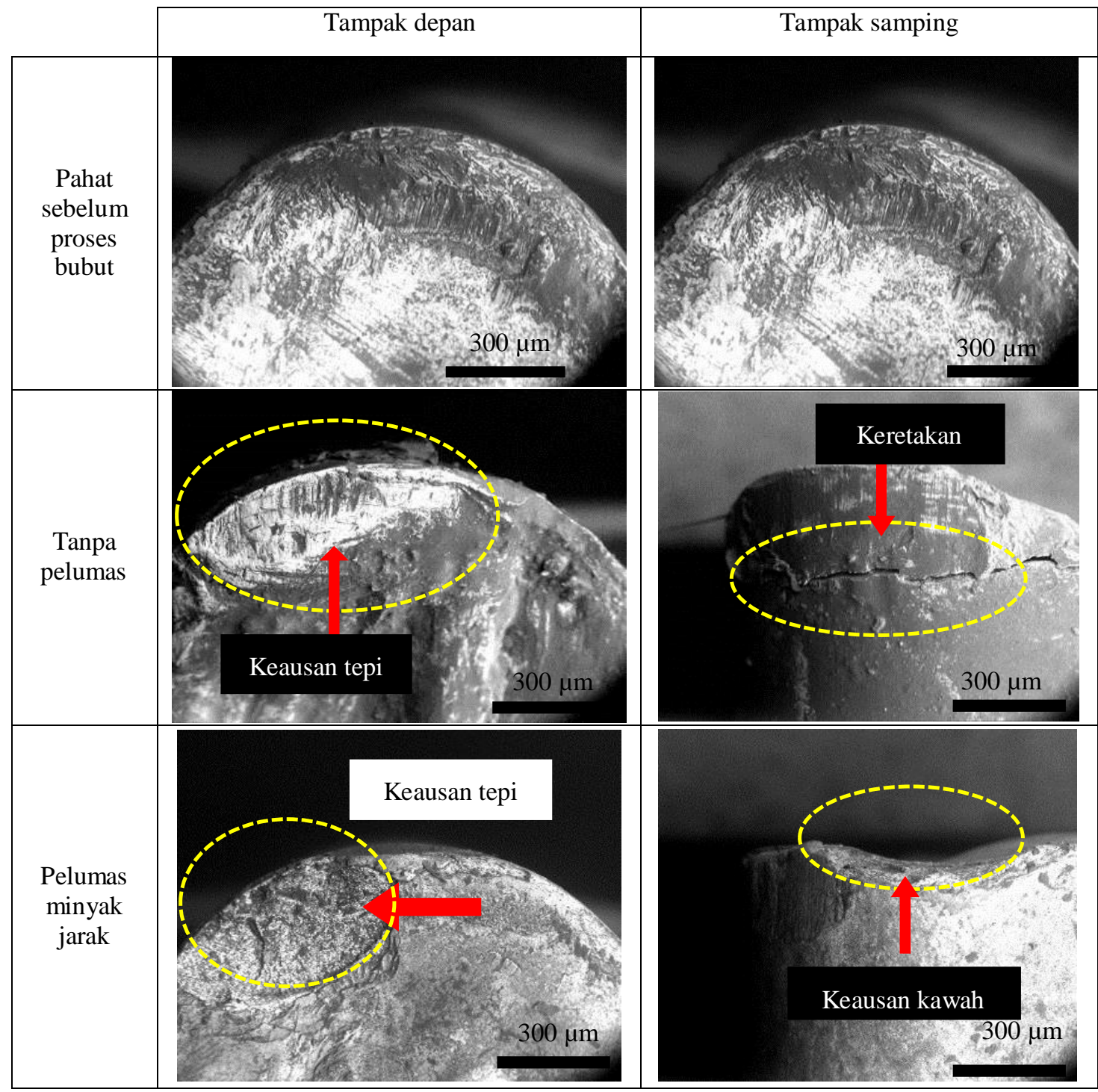




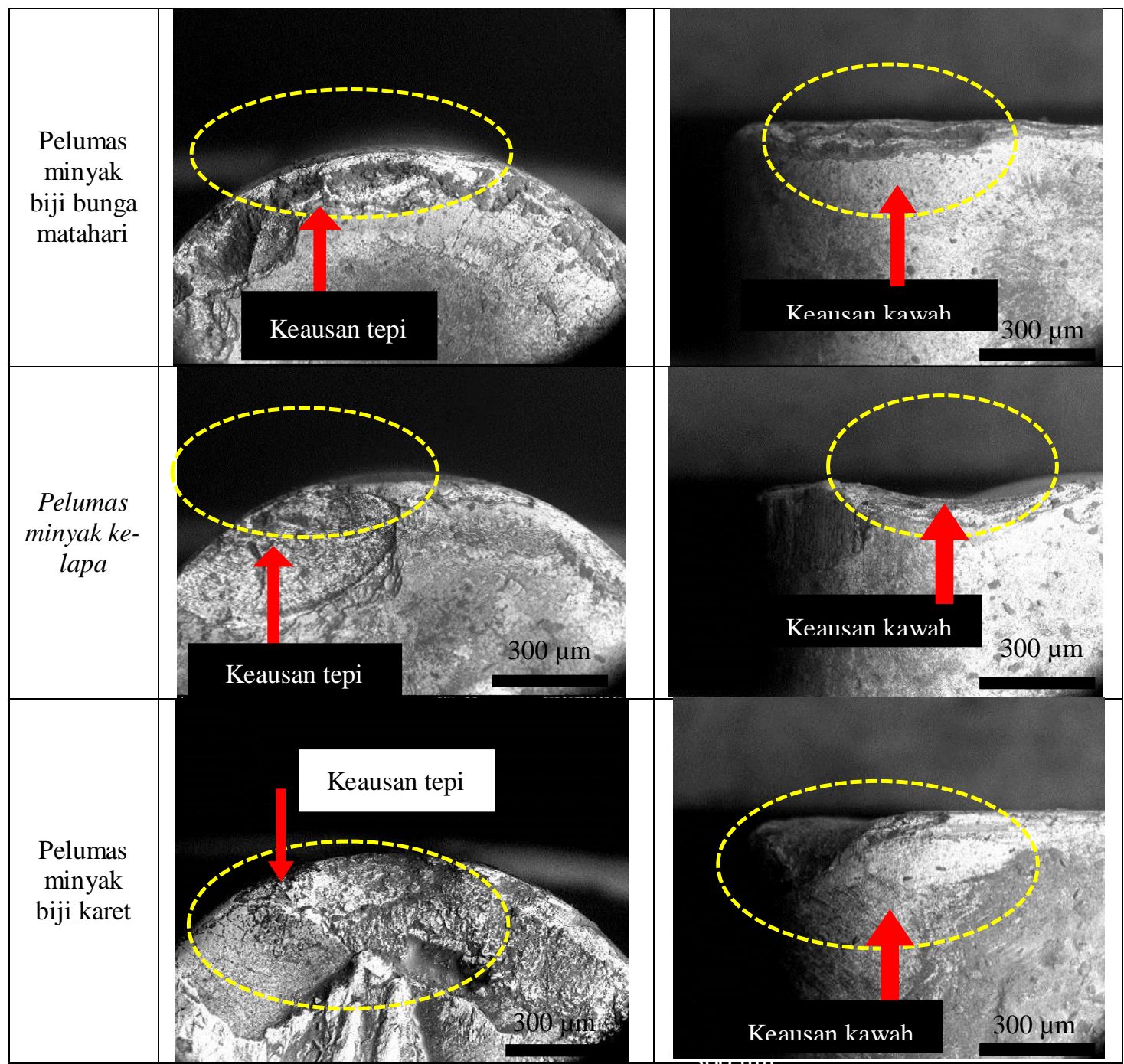

Gambar 3. Penampang permukaan pahat sebelum dan setelah dilakukan proses bubut dengan menggunakan berbagai pelumas

Gambar 3 menunjukkan foto mikrostuktur pahat karbida sebelum proses permesinan menggunakan mesin bubut. Nampak timbul keausan pada pahat setelah melalui proses permesinan. Keausan pahat diakibatkan karena gesekan antara pahat dan aluminium. Keausan pahat untuk specimen yang dibubut tanpa menggunakan pelumas mengalami keausan kawah dan retak menjalar dengan bertambahnya waktu yang digunakan untuk memotong. Hal ini disebabkan karena tidak adanya pelumasan ataupun pendinginan pada area bidang kontak antara pahat dan bidang kontak. Gesekan yang terjadi menyebabkan menimbulkan panas yang memicu terjadinya keausan. Sehingga keausan dapat menyebabkab kerusakan pada pahat yang mengakibatkan pada kasarnya permukaan benda kerja.

Sedangkan keausan pahat untuk specimen yang dibubut dengan menggunakan metode tetesan dengan pelumas minyak jarak mengalami pengurangan volume pahat sebesar $0,062828 \mathrm{~cm}^{3}$. Nilai tersebut relatif kecil jika dibandingkan dengan specimen yang dibubut tanpa menggunakan pelumas yang mengalami pengurangan volume pahat sebesar $0,170889 \mathrm{~cm}^{3}$. Dikarenakan lubricant mampu melumasi bidang area kontak antara mata pahat dengan aluminium 6061 dan mampu menghilangkan chip pada area bidang kontak yang menyebabkan keausan pahat akan mengecil sehingga nilai kekasaran permukaan cenderung lebih rendah.

Teknik minimum quantity lubrication dapat memperpanjang umur pahat dibandingkan tanpa menggunakan lubrication karena proses lubrikasinya menyebabkan berkurangnya gesekan pada bidang kontak antara pahat dengan benda kerja. Semakin kecil gesekan maka semakin kecil laju pemanasan pahat, sehingga hal ini akan membantu berkurangnya keausan pahat.

Keausan pahat dengan menggunakan pelumas minyak alami mengalami keausan yang berbeda-beda, keausan dominan terjadi pada sisi tepi dan kawah pahat. Adapun keausan pahat yang baik yaitu menggunakan pelumas minyak kelapa dengan pengurangan volume pahat sebesar $0,034421 \mathrm{~cm}^{3}$, semakin rendah nilai viskositas maka kemampuan untuk melumasi area bidang kontak akan lebih baik sehingga mampu untuk untuk menurunkan panas pada bidang kontak. Dibandingkan dengan pelumas minyak alami jenis minyak biji bunga 
matahari, minyak biji karet, minyak jarak. Pelumas minyak kelapa memiliki keausan yang rendah sehingga mampu untuk meningkatkan kwalitas permukaan aluminium 6061 yang lebih baik.

\section{KESIMPULAN}

Berdasarkan uraian pada pembahasan sebelumnya, maka dapat diambil kesimpulan terhadap pengaruh pelumas jenis minyak alami dengan menggunakan metode tetesan pada mesin bubut terhadap adalah sebagai berikut :

1. Pelumasan minyak alami menggunakan metode minimum quantity lubrication mempengaruhi kekasaran permukaan hasil proses bubut, dimana pelumasan menggunakan MQL memberikan hasil terbaik untuk penggunaan minyak kelapa dengan kekasaran permukaan sebesar $1.563 \mu \mathrm{m}$ dibandingkan dengan proses bubut tanpa menggunakan pelumas dengan kekasaran permukaan sebesar $2 \mu \mathrm{m}$.

2. Teknik metode tetesan dengan pelumas jenis minyak jarak menghasilkan keausan lebih rendah dibanding dengan tanpa pelumas. Dimana kemampuan untuk melumasi area bidang kontak antara pahat karbida dengan aluminium akan menimbulkan panas yang tinggi, sehingga metode tetesan untuk mengurangi keausan cukup baik dan bentuk geram yang dihasilkan dari metode tetesan menggunakan pelumas minyak kelapa dengan bentuk geram yang continous.

\section{DAFTAR PUSTAKA}

[1] SHARMA, A., JOSHI, S.S., DATTA, D., BALASUBRAMANIAM. R., "Investigation Of Tool and Workpiece Interaction On Surface Quality while Diamond Turning Of Copper Beryllium Alloy,", Journal Of Manufacturing Science Engineering, N. 142, N. 2, 021011, Feb. 2020.

[2] YILDIRIM, C.V., KIVAK, T., ERZINCANLI, F., "Tool Wear and Surface Roughness Analysis in Milling With Ceramic Tools of Waspaloy: A Comparison Of Machining Performance with Different Cooling Methods," Journal of The Brazilian Society of Mechanical Sciences and Engineering., v. 41, n. 83, 2019

[3] NOWAK, P., KUCHARSK, K., KAMIŃSKI, M., "Ecological and Health Effects Of Lubricant Oils Emitted Into The Environment," International Journal of Environmental Research Public Health, v. 16, n.16, 3002, Aug. 2019

[4] WOMA, Y.W., LAWAL. A.S., ABDULRAHMAN, S.A., OLUTOYE, M.A., OJAP, M. M., "Vegetable Oil Based Lubricants: Challenges and Prospects", Tribology Online, Vol. 14, No. 2, pp 60-70, 2019.

[5] CECILIA, A. J., PlATA, B. D., SABOYA, A. M. R., LUNA, D. T. M. F., CAVALCANTE, C. L., "An Overview Of The Biolubricant Production Process: Challenges And Future Perspectives", Enrique Rodríguez-Castellón, v. 8, n.3, 257, 2020.

[6] WerdaA, S., DUCHOSAlA, A., QUILlieCA, G. A., MORANDEAUB, A., LEROYA, R., "Minimum Quantity Lubrication: Influence Of The Oil Nature On Surface Integrity", 3rd CIRP Conference On Surface Integrity (CIRP CSI) Procedia CIRP, v. 45, pp. 287 - 290, 2016.

[7] SEN, B., MIA, M., KROLCZYK, G. M., MANDAL, K. U., MONDAL, P. S., "Eco-Friendly Cutting Fluids In Minimum Quantity Lubrication Assisted Machining: A Review On The Perception Of Sustainable Manufacturing", International Journal Of Precision Engineering And Manufacturing-Green Technology, v 8, pp 249-280, 2021.

[8] ARUL, K, KUMAR, V.S,.., "Magnetorheological Based Minimum Quantity Lubrication (Mr-MQL) With Additive N-Cuo", Materials And Manufacturing Processes, v. 35, Issue 4, pp 405-414, 2020

[9] MARTINEZ, G., MiGUEL, V., MARTINEZ, A., MANJABACAS, C. M., COELLO, J., "Sustainable Lubrication Methods For The Machining Of Titanium Alloys", Materials, vol. 12, 3852, 2019.

[10] PAMUJI, R. D., LUSI, N., "Optimasi Parameter Proses Bubut Material ST 60 Dengan Pendinginan Ramah Lingkungan Menggunakan Metode Taguchi-Grey”, Jurnal Rekayasa Mesin v. 10, n 3, pp. 245255, 2019.

[11] WIDIYAWATI, S., NOVAREZA, O., SULISTYARINI, D.H., PUTRO, W. W,"Pengaruh Penggunaan Cairan Pendingin (Coolant) Terhadap Keausan Pahat Bubut Hss", Jurnal Rekayasa Mesin v 11, n 3, pp. 467-475, 2020.

[12] GUNDA, K. R., NARALA, R. K. S., "Electrostatic High-Velocity Solid Lubricant Machining System For Performance Improvement Of Turning Ti-6Al-4V Alloy", Journal of Engineering Manufacture v. 233, n.1, pp 118-131, 2019.

[13] WEIHONG., W., WANG, S., TOMOVIC, M. M., "Mechanical Wear Debris Feature, Detection, And Diagnosis", Chinese Journal Of Aeronautics, v 31, Issue 5, pp 867-882, Mei. 2018.

[14] MABROKI, T., COURBON, C., ZHANG, Y., RECH, J., NAILIAS, D., ASAD, M., HAMDI, H., BELHADI, S., SALVATORE, F., "Some Insights On The Modelling Of Chip Formation And Its Morphology During Metal Cutting Operations", Comptes Rendus Mécanique, v 344, Issues 4-5, pp 335354, April-Mei. 2016. 
[15] GHOSH, P., PACELLA, M., "Effect Of Laser Texturing On The Performance Of Ultra-Hard Single-Point Cutting Tools", The International Journal Of Advanced Manufacturing Technology, v 106, pp 26352648, 2020. 